Aim of the study: The main purpose of this study is to assess the known adverse effects of adjuvant endocrine therapy for non-metastatic breast cancer patients and to present our single center experience with light of literature.

Material and methods: The breast cancer patients treated with adjuvant radiotherapy in Medical School of Ege University between January 2007 and December 2009 were evaluated for this trial after obtaining their acceptance. Vital findings, bone minera densitometry, endometrium thickness measured with trans-vaginal ultrasonography, biochemical results in cluding liver function tests and blood lipid profile (total cholesterol, HDL, LDL, VLDL, triglyceride) were recorded for each controls. Socio-demographic data, financial statuses, medical history, co-morbid diseases were obtained from first controls. Patients were followed without any local recurrence and distant metastases unti June 2011.

Results: Endometrium thickness was not seen in Al using patients. As compared with tamoxifen group, lack of thickness in Al group was statistically significant $(p=0.000)$. When compared the values before $\mathrm{Al}$, the number of patients who had osteoporosis was gradually increasing. The decrease was seen in the number of patients with osteopenia. The number of patients with normal lipid profile was gradually increasing up to the second evaluation for tamoxifen group ( $p=$ $=0.000$ ). On the other hand, the number of patients with hyperlipidemia was increasing for Als group in follow-up period statistically $(p=0.006)$. Conclusions: With the aid of careful patient follow and effective disease management strategies, the negative effect over the OoL can be minimized and also the greatest benefit from endocrine therapy can be obtained.

Contemp Oncol (Pozn) 2014; 18 (5): 344-348 DOI: $10.5114 /$ wo.2014.45245

\section{Adverse effects of endocrine therapy in breast cancer: single institute experience}

Fatma Sert ${ }^{1}$, Zeynep Ozsaran ${ }^{1}$, Erhan Esen ${ }^{1}$, Senem Alanyalı ${ }^{2}$, Ismail Sert ${ }^{3}$, Ayfer Haydaoglu ${ }^{1}$, Arif Aras $^{1}$

'Department of Radiation Oncology, Ege University, İmir, Turkey ${ }^{2}$ Department of Public Health, Celal Bayar University, Manisa, Turkey ${ }^{3}$ Department of General Surgery Tepecik, Training and Research Hospital, İzmir, Turkey

\section{Introduction}

Breast cancer is the most common type of cancer and it is the second most common cause of cancer death among women [1, 2]. In recent years advanced techniques have helped facilitate early-stage diagnosis of breast cancer and have prolonged the survival of patients with this disease. Long survival expectancy brings also the concept of quality of life (QoL) [3]. Breast cancer treatment includes a combination of surgery, chemotherapy, radiotherapy, and endocrine therapy. Adjuvant endocrine therapy (AET) is applied to hormone receptor-positive patients. AET is generally well tolerated and is not associated with acute or serious adverse effects, which are seen in chemotherapy. However, the need for long-term usage is a disadvantage of AET. Regular use is required to obtain the benefits of AET. Endocrine therapy is not only used in breast cancer but also in ovarian cancer [4]. Therefore, management of the adverse effects of AET composes an important part of treatment.

Clinical trials report that Als and tamoxifen are well tolerated and that they do not negatively influence patients' routine life. Additionally, the results of FACE (comparing anastrozole and letrozole) and MA.27 (comparing exemestane and anastrozole), which are comparing Als with each other directly, are pending, but thus far no differences between Als have been found.

Notwithstanding the proven activities and acceptable tolerability profiles of endocrine treatment approaches, their adverse effects are generally underestimated $[5,6]$. The main purpose of this study is to assess the known adverse effects of AET for non-metastatic breast cancer patients and to present our single-centre experience in light of the literature. We planned to give confirmatory results of hormonal treatment side effects before QoL evaluations.

\section{Material and methods}

Breast cancer patients treated in the Medical School of Ege University between January 2007 and December 2009 were evaluated for this trial after obtaining their approval. All of the included patients completed the whole treatment deemed appropriate for cancer, except for endocrine therapy.

\section{Assessments}

The patients were assessed in their routine policlinic controls. Vital findings, bone mineral densitometry (BMD), endometrial thickness measured with trans-vaginal ultrasonography (TVUSG), and biochemical results including liver function tests and blood lipid profile (total cholesterol, HDL (high-density lipoproteins), LDL (low-density lipoproteins), VLDL (very low-density lipoproteins), triglyceride), were recorded. First evaluation was 
done after applying whole adjuvant cancer treatment except hormonal therapy, and it was coded as 'basal assessment'. Second evaluations were done after 6-12 months from the first control. Last evaluations were obtained within 18-24 months of the follow-up period.

\section{Statistical analyses}

Data were analysed using SPSS v15 (Statistical Package for Social Sciences version 15, SPSS Inc., Chicago, USA). For measuring descriptive statistics, frequency of distributions, average of whole scores, and 'Student's $t$ test' were used to compare socio-demographic variables, clinical

Table 1. Clinical features of patients

\begin{tabular}{|c|c|c|}
\hline & Number & $\%$ \\
\hline $\begin{array}{l}\text { Menopausal status } \\
\text { Premenopausal } \\
\text { Postmenopausal }\end{array}$ & $\begin{array}{l}56 \\
66\end{array}$ & $\begin{array}{l}45.9 \\
54.1\end{array}$ \\
\hline $\begin{array}{l}\text { Co-morbid disease } \\
(+) \\
(-)\end{array}$ & $\begin{array}{l}58 \\
64\end{array}$ & $\begin{array}{l}47.5 \\
52.5\end{array}$ \\
\hline $\begin{array}{l}\text { Operation type } \\
\text { Partial mastectomy } \\
\text { Total mastectomy }\end{array}$ & $\begin{array}{l}78 \\
44\end{array}$ & $\begin{array}{l}63.9 \\
36.1\end{array}$ \\
\hline $\begin{array}{l}\text { Hormone receptor level } \\
\text { Positive } \\
\text { Negative }\end{array}$ & $\begin{array}{c}102 \\
20\end{array}$ & $\begin{array}{l}83.6 \\
16.4\end{array}$ \\
\hline $\begin{array}{l}\text { Axillary dissection } \\
(+) \\
(-)\end{array}$ & $\begin{array}{l}80 \\
42\end{array}$ & $\begin{array}{l}65.6 \\
34.4\end{array}$ \\
\hline $\begin{array}{l}\text { Stage group } \\
\text { Early stage } \\
\text { Locally advanced stage }\end{array}$ & $\begin{array}{l}95 \\
27\end{array}$ & $\begin{array}{l}77.9 \\
22.1\end{array}$ \\
\hline $\begin{array}{l}\text { Chemotherapy } \\
(+) \\
(-)\end{array}$ & $\begin{array}{l}84 \\
38\end{array}$ & $\begin{array}{l}68.9 \\
31.1\end{array}$ \\
\hline $\begin{array}{l}\text { Hormonal treatment type } \\
(-) \\
\text { Tamoxifen Group } \\
\text { Aromatase Inhibitors }\end{array}$ & $\begin{array}{l}19 \\
50 \\
51\end{array}$ & $\begin{array}{l}15.6 \\
41.0 \\
43.5\end{array}$ \\
\hline
\end{tabular}

For Tamoxifen Group

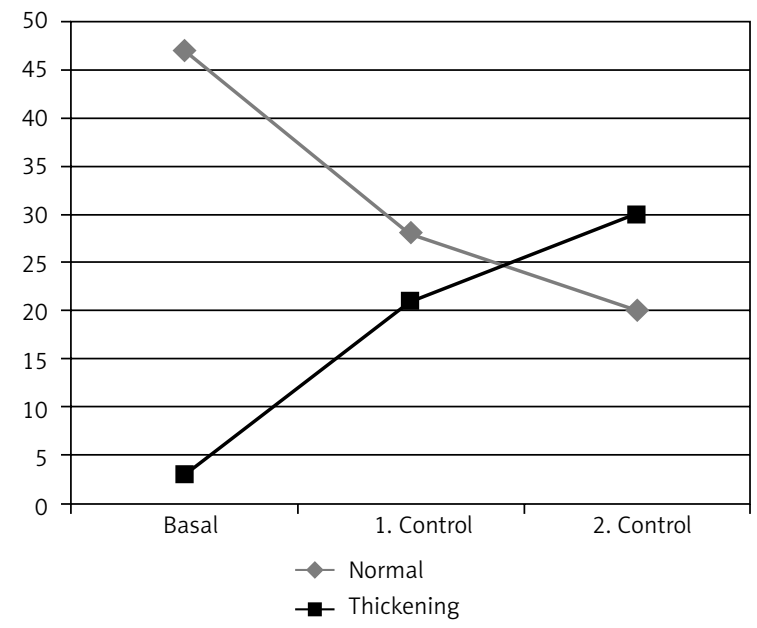

Fig. 1. Evaluation of endometrial thickness variables, and adverse effect data. In the analyses $p \leq 0.05$ was accepted as statistically significant.

\section{Results}

One hundred and twenty-two breast cancer patients were included in this research. Clinical features of patients are illustrated in Table 1.

\section{Evaluation of endometrial thickness}

Endometrial thickness changes were measured with TVUSG for 50 patients using tamoxifen during the follow-up period as shown in Fig. 1. Before tamoxifen therapy, three patients had thickening of the endometrium in basal evaluation. After tamoxifen therapy, this number increased to $30(p=0.000)$. The detected rise was seen as statistically significant. All patients were referred to a gynaecologist for vaginal curettage. The results of curettages were reported as endometrial hyperplasia, except for in one patient. That patient's pathologic result included not only hyperplasia but also single invasive focus. Operation was suggested and applied with the patients' approval. Endometrial thickness was not seen in Al-using patients. Compared to the tamoxifen group, the lack of thickness in Al group was statistically significant $(p=0.000)$.

\section{Evaluation of bone loss}

$\mathrm{BMD}$ results for the $\mathrm{Al}$ group are shown in Fig. 2. When compared the values before Al, the number of patients who had osteoporosis gradually increased during therapy. A decrease was seen in patients with osteopaenia. These results were interpreted as the osteopaenia results shifting towards the osteoporosis side by use of Als. BMD data for the tamoxifen group are also shown in Fig. 2. No significant change was seen during the follow-up period.

\section{Evaluation of lipid profiles}

The number of patients with normal lipid profile was gradually increasing up to the second evaluation for the

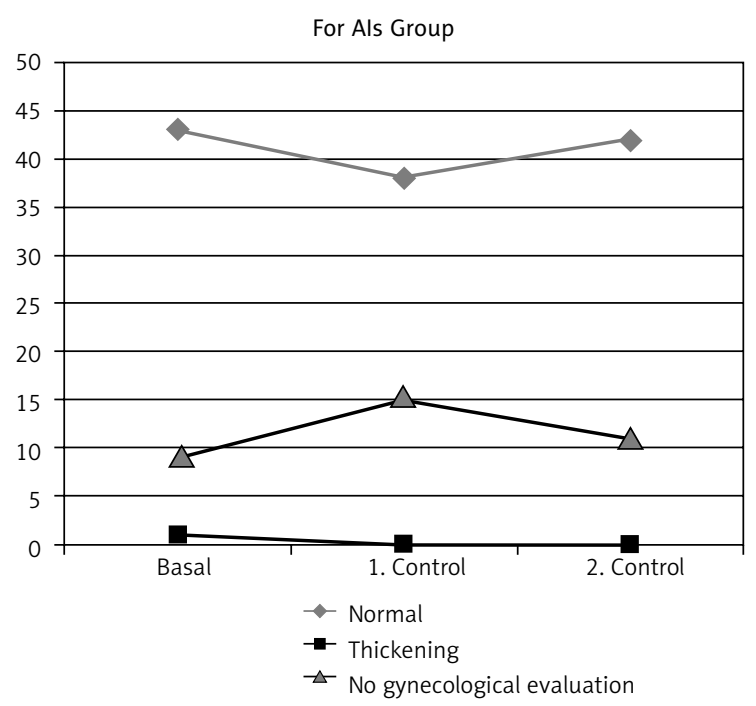



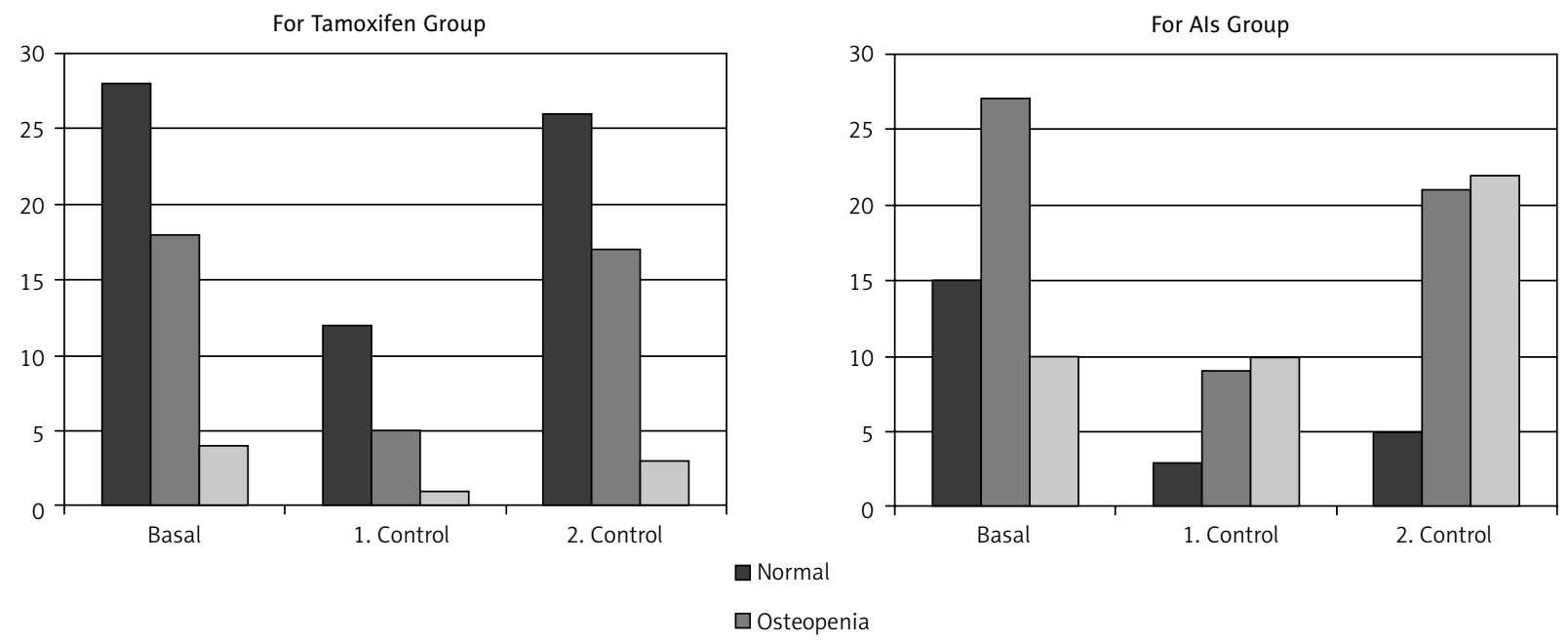

Fig. 2. Evaluation of bone loss

$\square$ Osteoporosis

tamoxifen group $(p=0.000)$. Blood lipid profile changes for the tamoxifen group can be seen in Fig. 3. On the other hand, the number of patients with hyperlipidaemia increased for the Al group in the follow-up period $(p=0.006)$.

\section{Discussion}

Vaginal bleeding is an important symptom that can significantly affect the routine life of a patient. It is often associated with thickening of the endometrium. The probability of endometrium cancers should be considered. Tamoxifen was found to be associated with vaginal bleeding and endometrial thickness in The Arimidex, Tamoxifen Alone or in Combination (ATAC) and The Breast International Group (BIG) 1-98 studies [7, 8]. Vaginal bleeding caused by endometrial thickening was detected in $5.4 \%$ of the anastrozole group and $10.2 \%$ in the tamoxifen group ( $p<0.0001$ ). According to BIG 1-98 data, this ratio was 3.3\% for the letrozole group and $6.6 \%$ for the tamoxifen group $(p<0.001)$. However, no statistical difference between tamoxifen and anastrozole arms was found in terms of vaginal bleeding and endometrium thickness in the com-

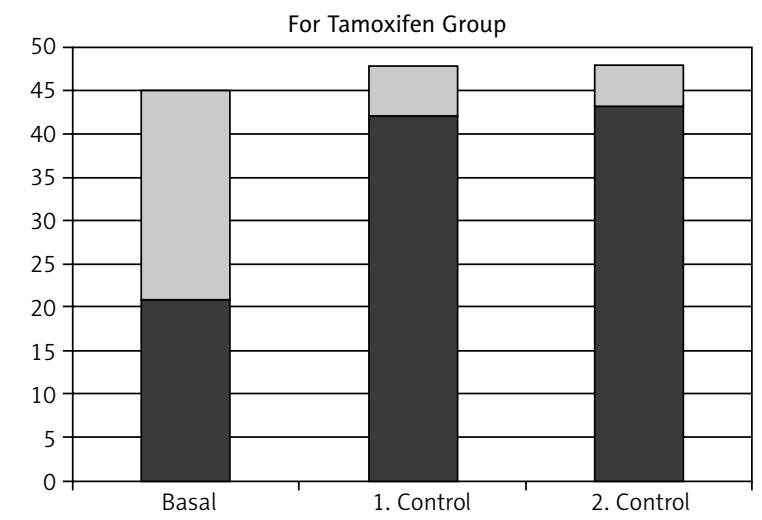

\section{$\square$ Hyperlipidemia}

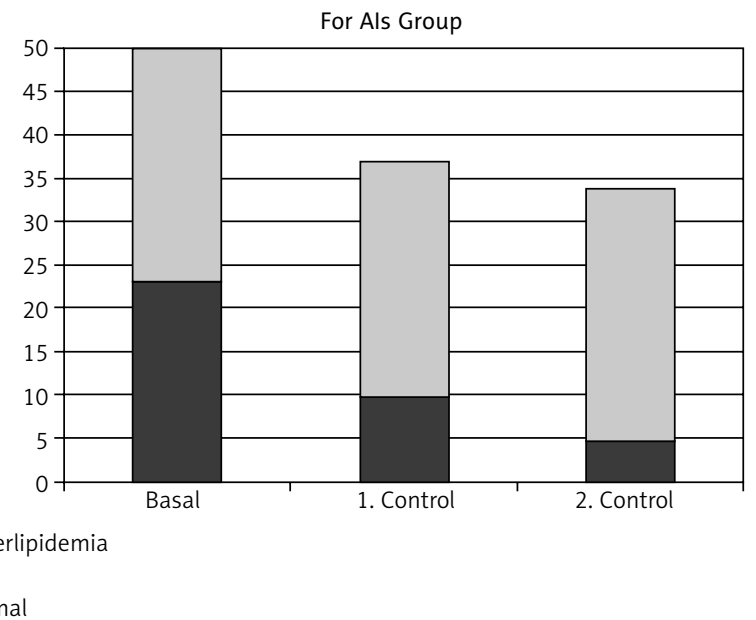

Normal

bined analysis of the Austrian Breast and Colorectal Cancer Study Group 8 (ABCSG8) and Arimidex-Nolvadex 95 (ARNO95) trials [9]. The International Exemestane Study (IES) reported that increased endometrium thickness and vaginal bleeding was seen in the tamoxifen group than in the exemestane group ( $p=0.05)$ [10]. Greater endometrial thickness and bleeding were determined in the placebo arm than in the letrozole arm in the MA.17 study $(8 \%$ versus $6 \%, p=0.005)$. The researchers argued the view that Al could repress the endometrial proliferation [11]. Endometrium thickness was detected only in three patients using tamoxifen before AET in our study. After tamoxifen therapy, the number of patients with endometrial thickness increased to 30 in the control assessment. This result was similar to that seen in the literature $(p=0.000)$.

BMD is a good indicator for osteoporosis evaluation. According to literature, Als can cause an annual 2-3\% decrease in BMD [12]. Postmenopausal BMD loss is increased with Als. This can be explained by the increase in bone resorption through Als. BMD data were investigated in ATAC subgroup analysis evaluating osteoporosis [13]. Osteopo-

Fig. 3. Evaluation of lipid profiles 
rosis was seen $3.3 \%$ more often in the tamoxifen group than in the anastrozole group. The osteoporosis rate was $11 \%$ for the anastrozole arm and $7.7 \%$ for the tamoxifen arm $(p<0.0001)$. BMD and bone pain were assessed after five years of follow-up for women using tamoxifen for 2-3 years followed by anastrozole in the ARNO95/ABCSG8 combined trial [9]. A significantly higher rate of osteoporosis was seen in the arm that switched to anastrozole (2\%) than in the the tamoxifen $\operatorname{arm}(p=0.015)$. More bone pain was reported in the anastrozole arm (19\% vs. $16 \%$, $p=0.05)$. Bone fractures were detected more often in the letrozole arm than in the tamoxifen arm in the BIG 1-98 trial $(p<0.001)$ [8]. BMD results of patients using Als, before and after endocrine therapy, were compared in our study in order to evaluate osteoporosis. There was no significant difference between basal (obtained before endocrine therapies) and first control results. On the other hand, it was seen that osteoporosis was statistically higher in the second evaluation $(p=0.000)$.

The effect of Als upon blood lipid levels is another issue to be discussed. Blood lipid profile changes were compared between the patients using tamoxifen alone and the patients using anastrozole after 5 years of tamoxifen in the Italian Tamoxifen Anastrozole (ITA) trial [14]. Statistically significant blood lipid profile changes were seen in the anastrozole group ( $9.3 \%$ vs. $4.0 \%, p=0.03$ ). However, there was no difference regarding hypercholesterolaemia in the anastrozole arm according to the ARNO95/ABCSG8 study results [9]. The effect of exemestane on blood lipid profile was evaluated in a randomised controlled study by Krang et al. [15], in which placebo and exemestane arms were compared. While the value of $\mathrm{HDL}-\mathrm{C}$ decreased by $6-9 \%$ in the exemestane arm, there was a $1-2 \%$ increase in the placebo arm $(p<0.001)$. Blood lipid profile differences were compared between placebo and letrozole arms in a 36-month follow-up in the MA.17 trial $[11,16]$. There were no statistically significant differences in terms of total cholesterol, HDL-C, LDL-C, triglyceride, or lipoprotein A levels between the two arms. Three hundred and forty patients were included in the Adjuvant Post-Tamoxifen Exemestane vs. Nothing Applied (ATENA) study [17]. A patient group using exemestane for 5 years and a patient group using nothing after 5-7 years of tamoxifen were compared in the ATENA study. There was no difference in subgroup analysis of ATENA in terms of total cholesterol, LDL-C, HDL-C, and triglyceride levels. We detected that blood lipid levels were gradually increasing in the Al group during the follow-up period ( $p=0.006)$. This increasing result was seen similarly in the ARN095/ABCSG8 trial and in the study by Krang et al.

In conclusion, most of the adverse effects of endocrine therapy consist of oestrogen suppression, as well as the side effects of predicted natural menopause. Nevertheless, these adverse effects can still be annoying and troublesome in the patients' routine daily life. Effective management options are available in order to cope with undesired side effects of Al treatment. On the other hand, the management of the side effects derived from tamoxifen is more difficult than for Al. Side effects experienced with Al, like bone loss, lipid profile changes and arthralgia, are controlled and managed easier than the effects, like thromboembolic events and endometrium cancer, experienced primarily with tamoxifen. With the aid of careful patient follow-up and effective disease management strategies, the negative effect on the patients' routine daily life can be minimised and the greatest benefit from endocrine therapy can be obtained. In order to give certain behaviour approaches, we need multi-institutional research projects on large numbers of people, including QoL assessments. With the help of future research, we can improve the disease prognosis through increased treatment adherence and belief of patients.

\section{The authors declare no conflict of interest.}

\section{References}

1. American Cancer Society: Cancer Facts and Figures 2007-2008. American Cancer Society; Atlanta: 2008; 2-8.

2. Jemal A, Siegel R, Ward E, Murray T, Xu J, Smigal C, Thun MJ.Cancer Statistics, 2006. CA Cancer J Clin 2006; 56:106-30.

3. Julie L, Pamela J, Louise J, Sophie L, Valérie T. Quality-of-life measurement in randomized clinical trials in breast cancer: an updated systematic review (2001-2009). J Natl Cancer Inst 2011; 103 : 178-231.

4. Serkies K, Sinacki M, Jassem J. The role of hormonal factors and endocrine therapy in ovarian cancer. Contemp Oncol (Pozn) 2013; 17: 14-9.

5 Sloan JA, Cella D, Frost M, Guyatt GH, Sprangers M, Symonds T; Clinical Significance Consensus Meeting Group. Assessing clinical significance in measuring oncology patient quality of life: Introduction to the symposium content overview and definition of terms. Mayo Clin Proc 2002; 77: 367-70.

6. van der Steeg AF, De Vries J, Roukema JA. Quality of life and health status in breast carcinoma. Eur J Surg Oncol 2004; 30: 1051-7.

7. Howell A, Cuzick J, Baum M, et al.; ATAC Trialists' Group. Results of the ATAC (Arimidex, Tamoxifen Alone or in Combination) trial after completion of 5 years' adjuvant treatment for breast cancer. Lancet 2005; 365: 60-2.

8. Thürlimann B, Keshaviah A, Coates AS, et al.; Breast International Group (BIG) 1-98 Collaborative Group,. A comparison of letrozole and tamoxifen in postmenopausal women with early breast cancer. N Engl J Med 2005; 353: 2747-57.

9. Jakesz R, Jonat W, Gnant M, et al.; ABCSG and the GABG. Switching of postmenopausal women with endocrine-responsive early breast cancer to anastrozole after 2 years' adjuvant tamoxifen: combined results of ABCSG trial 8 and ARNO 95 trial. Lancet 2005; 366: 455-62.

10. Coombes RC, Hall E, Gibson LJ, et al.; Intergroup Exemestane Study. A randomized trial of exemestane after two to three years of tamoxifen therapy in postmenopausal women with primary breast cancer. N Engl J Med 2004; 350: 1081-92.

11. Goss PE, Ingle JN, Martino S, et al. Randomized trial of letrozole following tamoxifen as extended adjuvant therapy in receptor-positive breast cancer: updated findings from NCIC CTG MA 17. J Natl Cancer Inst 2005; 97: 1262-71.

12. Venturini M, Del Mastro L. Safety of adjuvant aromatase inhibitor therapy. Cancer Treat Rev 2006; 32: 548-56.

13. Coleman RE on behalf of the ATAC Trialists' Group. Effect of anastrozole on bone mineral density: 5-year results from the 'Arimidex', 'Tamoxifen', Alone or in Combination (ATAC) trial. J Clin Oncol 2006; 24: 18 (abstract).

14. Boccardo F, Rubagotti A, Puntoni M, et al. Switching to anastrozole versus continued tamoxifen treatment of early breast cancer: preliminary results of the Italian Tamoxifen Anastrozole Trial. J Clin Oncol 2005; 23: 5138-47. 
15. Lønning PE, Geisler J, Krag LE, et al. Effects of exemestane administered for 2 years versus placebo on bone mineral density, bone biomarkers, and plasma lipids in patients with surgically resected early breast cancer. J Clin Oncol 2005; 23: 5126-37.

16. Wasan KM, Goss PE, Pritchard PH, et al. The influence of letrozole on serum lipid concentrations in postmenopausal women with primary breast cancer who have completed 5 years of adjuvant tamoxifen (NCIC CTG MA.17L). Ann Oncol. 2005; 16: 707-15.

17. Markopoulos C, Chrissochou M, Michailidou A, et al. Effects of exemestane on the lipidemic profile of postmenopausal operable breast cancer patients following 5-7 years of adjuvant tamoxifen: preliminary results of the ATENA sub-study. Anticancer Drugs 2005; 16: 879-83.

\section{Address for correspondence}

Fatma Sert

Üniversite caddesi Ege üniversitesi Tıp fakültesi Hastanesi

Radyasyon Onkolojisi Kliniği

35100 izmir, Turkey

Submitted: 5.11 .2013

Accepted: 9.06 .2014 